\title{
Effect of transparent electrode on the performance of bulk heterojunction solar cells
}

\author{
A. A. Damitha T. Adikaari ${ }^{1 *}$, Joe Briscoe ${ }^{2}$, Steve Dunn $^{3}$, J. David Carey ${ }^{1}$ and S. Ravi P. Silva ${ }^{1}$ \\ ${ }^{1}$ Nanoelectronics Centre, Advanced Technology Institute, University of Surrey, Guildford GU2 \\ 7XH, UK. \\ ${ }^{2}$ Nanotechnology Centre, Cranfield University, Cranfield, MK43 OAL, UK. \\ ${ }^{3}$ Materials Department, School of Engineering and Materials, Queen Mary, University of \\ London, E1 4NS, UK. \\ *Corresponding author email:d.adikaari@surrey.ac.uk
}

\begin{abstract}
We present a performance comparison of polythiophene/fullerene derivative bulk heterojunction solar cells fabricated on fluorinated tin oxide (FTO) and indium tin oxide (ITO) in the presence and absence of the commonly used poly(3,4-ethylenedioxythiophene): poly(styrenesulfonate) (PEDOT:PSS) hole extraction layer. From a potential commercial perspective the performance of cheaper and more readily available FTO compares well with the more expensive ITO in terms of measured device efficiency (FTO:2.8 \% and ITO:3.1\%). The devices show similar fill factors (FTO:63\% and ITO:64\%) with the same open circuit voltage of $0.6 \mathrm{~V}$. The short circuit current density is lower for FTO devices at $7.5 \mathrm{~mA} / \mathrm{cm}^{2}$ which compares with $8.0 \mathrm{~mA} / \mathrm{cm}^{2}$ for ITO; a behaviour that is mainly attributed to the reduced optical transmission of the FTO layer. Importantly, these devices were part fabricated and wholly characterized under atmospheric conditions. The quoted device performance is the best reported for FTO based bulk heterojunction systems in the absence of the highly acidic PEDOT:PSS hole extraction layer, which is believed to degrade conductive oxides.
\end{abstract}

\section{INTRODUCTION}

Renewable energy is one of the key routes to minimize the adverse effects of carbon emission from energy conversion. The conversion of the sun's radiation to electricity by photovoltaics (PVs) offers one of the most credible alternatives for renewable energy needs provided the efficiency of the PVs can be increased while decreasing the cost. Silicon based PVs dominate $90 \%$ of the commercial market,[1] however the technology remains too expensive for mass uptake. Organic material-based PVs are cheaper and not as-energy intensive in terms of the production process. Furthermore, the possibility of facile device fabrication from solution makes the technology very attractive from a potential commercial perspective. However, the efficiencies and lifetimes of organic PV devices are inferior to their conventional inorganic semiconductor counterparts and are too low for commercial viability at present.

Interpenetrating charge donor-acceptor networks formed from a phase-segregated mixture of two semiconducting organic materials are considered to be the best architecture for fabrication of organic PVs to date[2, 3]. These interpenetrating networks are now known as bulkheterojunction active layers. Bulk heterojunction PV devices fabricated have shown steady 
progress over the years [4-6], in terms of device efficiency, reaching a maximum of $7.73 \%$ in 2009 for a single junction device [7]. A vast majority of the bulk-heterojunction organic PV research has been on Poly (3-Hexylthiophene) (P3HT) donor and [6,6]-phenyl-C61-butyric acid methyl ester (PCBM) acceptor systems, coated on indium doped tin oxide (ITO) covered transparent substrates.

However, ITO is expensive to produce and it has been the standard to coat it with poly(3,4-ethylenedioxythiophene):poly(styrenesulfonate) (PEDOT:PSS) as a hole extraction layer for organic PV applications. Relatively few studies have focused on the development of alternative materials for use in OPV devices[8-12]. From these studies, fluorine-doped $\mathrm{SnO}_{2}$ (FTO) is a possible alternative to ITO because $\mathrm{SnO}_{2}$ films are inexpensive to produce and chemically and thermally stable. We report a performance comparison of ITO and FTO based P3HT and [6,6]-phenyl-C71-butyric acid methyl ester $\left(\mathrm{PC}_{70} \mathrm{BM}\right)$ bulk heterojunction PVs with and without PEDOT:PSS with comparatively higher efficiencies than reported values.

\section{EXPERIMENTAL}

Photovoltaic devices were fabricated on ITO coated glass substrates (Luminescence Technology Corporation, Taiwan, $150 \mathrm{~nm}, 15 \Omega / \square$ ) and FTO coated glass substrates (Pilkington USA, TEC $15,300 \mathrm{~nm}, 15 \Omega / \square)$. The substrates were ultrasonically cleaned with acetone followed by methanol and treated with oxygen plasma for five minutes, before spinning $30 \mathrm{~nm}$ of PEDOT:PSS (H.C. Starck Clevios $\mathrm{GmbH}$ ) at $3000 \mathrm{rpm}$ for 60 seconds and drying at $140^{\circ} \mathrm{C}$ for 10 minutes. A reference set of samples was also used without the PEDOT:PSS layer. The active layers were spin coated on all four types of substrates from a blend of P3HT (24 mg): $\mathrm{PC}_{70} \mathrm{BM}$ (24mg) in $1 \mathrm{ml}$ of 1-2 dichlorobenzene, stirred for a day on a magnetic stirrer with a stirring flea. A two step spin coating recipe was used yielding $~ 130 \mathrm{~nm}$ thick coating; the first at $800 \mathrm{rpm}$ for 40 seconds and second at $1500 \mathrm{rpm}$ for three seconds. The spin coated films were allowed to dry slowly in a closed glass Petri dish pair (60 mm diameter, $15 \mathrm{~mm}$ height) at room temperature and annealed at $125^{\circ} \mathrm{C}$ for 10 minutes. The active layer coating process was carried out in a nitrogen filled MBRAUN glove box with oxygen and water content less than $10 \mathrm{ppm}$. Bathocuproine $(\mathrm{BCP}, 8 \mathrm{~nm})$ was used as a hole blocking layer and an $\mathrm{Al}(80 \mathrm{~nm})$ electrode was thermally evaporated using a shadow mask at $8 \times 10^{-6}$ mbar at the rate of $2 \AA / s$ and $3 \AA$ \& $/ \mathrm{s}$, respectively. The current voltage characteristics of the devices were measured using an Oriel 81160 solar simulator for AM 1.5G simulation while current-voltage measurements were collected with a Keithley 2425 source meter. A separate set of partial devices were characterised for optical transmission using a Varian Cary 5000 spectrophotometer.

\section{DISCUSSION}

Figure 1 shows the current density-voltage characteristics measured under dark condition for all for configurations of $\mathrm{P} 3 \mathrm{HT}: \mathrm{PC}_{70} \mathrm{BM}$ bulk heterojunction solar cells investigated. The turnon voltages for the diodes are similar; however, the series resistances of devices on FTO are higher compared with the ITO based devices. Furthermore, the series resistances for both FTO and ITO based structures have increased in the presence of PEDOT:PSS. Although the less conductive PEDOT:PSS layer is thin $(30 \mathrm{~nm})$, the increase in series resistance for FTO based devices appears to be considerable. 


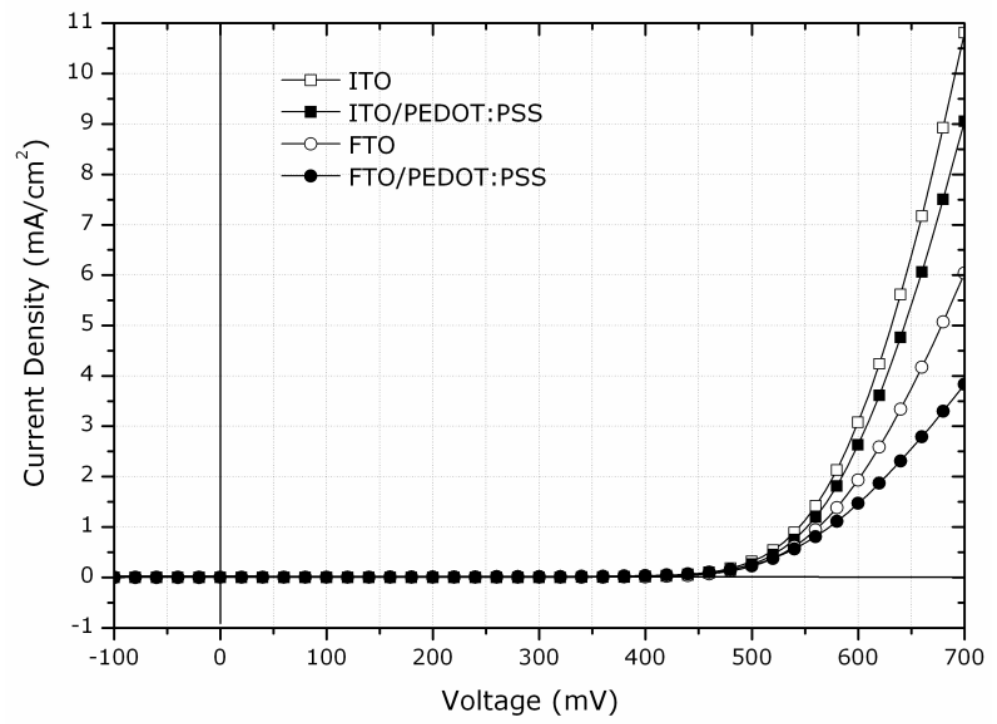

Figure 1. Current density-voltage characteristics in the dark for $\mathrm{P} 3 \mathrm{HT}: \mathrm{PC}_{70} \mathrm{BM}$ bulk heterojunction solar cells.

Figure 2 shows the current density-voltage characteristics under AM 1.5G simulated irradiation for the same sets of devices. It can be observed that, contrary to many reports available, our fabrication procedure yields better output characteristics without the hole extracting PEDOT:PSS layer for both FTO and ITO systems. The short circuit current density $\left(\mathrm{J}_{\mathrm{sc}}\right)$, open circuit voltage $\left(\mathrm{V}_{\mathrm{oc}}\right)$, current density and the voltage at the maximum power point were extracted from the data, and were used to calculate the fill factor $(\mathrm{FF})$ and the power conversion efficiency $(\eta)$ of devices under test, parameters which are fundamental for comparison. Table 1 shows the comparison of performance parameters for the four types of devices tested in our study.

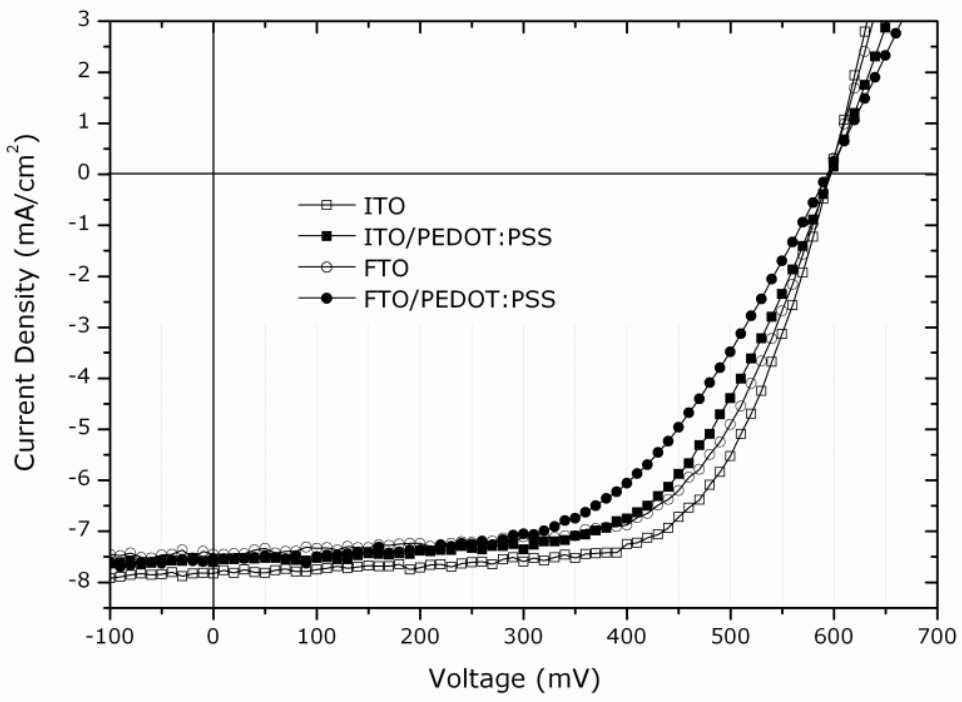

Figure 2. Current density-voltage characteristics under AM 1.5G simulated irradiation for $\mathrm{P} 3 \mathrm{HT}: \mathrm{PC}_{70} \mathrm{BM}$ bulk heterojunction solar cells. 
Table 1. Performance parameters of bulk heterojunction solar cells extracted from currentvoltage characteristics under AM 1.5G simulated irradiation.

\begin{tabular}{|l|c|c|c|c|c|}
\hline Architecture & $\begin{array}{c}\text { Area } \\
\left(\mathrm{cm}^{2}\right)\end{array}$ & $\begin{array}{c}\mathrm{V}_{\mathrm{oc}} \\
(\mathrm{V})\end{array}$ & $\begin{array}{c}\mathrm{J}_{\mathrm{sc}} \\
\left(\mathrm{mA} / \mathrm{cm}^{2}\right)\end{array}$ & $\begin{array}{c}\mathrm{FF} \\
(\%)\end{array}$ & $\eta(\%)$ \\
\hline Glass/ITO/P3HT:PCBM/BCP/Al & 0.78 & 0.60 & 7.95 & 64 & 3.06 \\
\hline Glass/ITO/PEDOT:PSS/P3HT:PCBM/BCP/Al & 0.78 & 0.60 & 7.64 & 60 & 2.73 \\
\hline Glass/FTO/P3HT:PCBM/BCP/Al & 0.70 & 0.60 & 7.45 & 63 & 2.82 \\
\hline Glass/FTO/PEDOT:PSS/P3HT:PCBM/BCP/Al & 0.70 & 0.60 & 7.59 & 54 & 2.45 \\
\hline
\end{tabular}

The $\mathrm{V}_{\mathrm{oc}}$, which is fundamentally governed by the highest occupied molecular orbital of the acceptor and the lowest unoccupied molecular orbital of the donor, is the identical for all four devices. It can be seen that the best device is glass/ITO/P3HT:PCBM/BCP/Al, which does not utilize a hole extraction layer. Although the presence of PEDOT:PSS lowers the $\mathrm{J}_{\mathrm{sc}}$ for ITO coated sample which is contrary to what is observed for devices using FTO. The change in $\mathrm{J}_{\mathrm{sc}}$ is small with and without the hole extraction layer, and lower for FTO devices. This can be explained with the optical transmission spectra for FTO/ITO with and without active layer as shown in figure 3 . The absorption of FTO is $2-5 \%$ higher in the region concerned $(0.4$ to $0.7 \mu \mathrm{m})$ compared with ITO, leading to lower $\mathbf{J}_{\mathrm{sc}}$. The higher absorption is partly due to twice the thickness of FTO compared to ITO, necessary for achieving similar sheet resistivities.

The FFs are better for cells without PEDOT:PSS, which suggests that the interfaces at ITO/FTO and BCP with active layer are optimal in this configuration. For both FTO and ITO, the FFs are similar suggesting that the work function difference between FTO $(4.4 \mathrm{eV})$ and ITO $(4.7 \mathrm{eV})[13]$ has an insignificant effect on the device architecture used. The quoted device performance is the best reported realistic efficiency for FTO based bulk heterojunction systems in the absence of the highly acidic PEDOT:PSS hole extraction layer which is believed to degrade conductive oxides. [12]

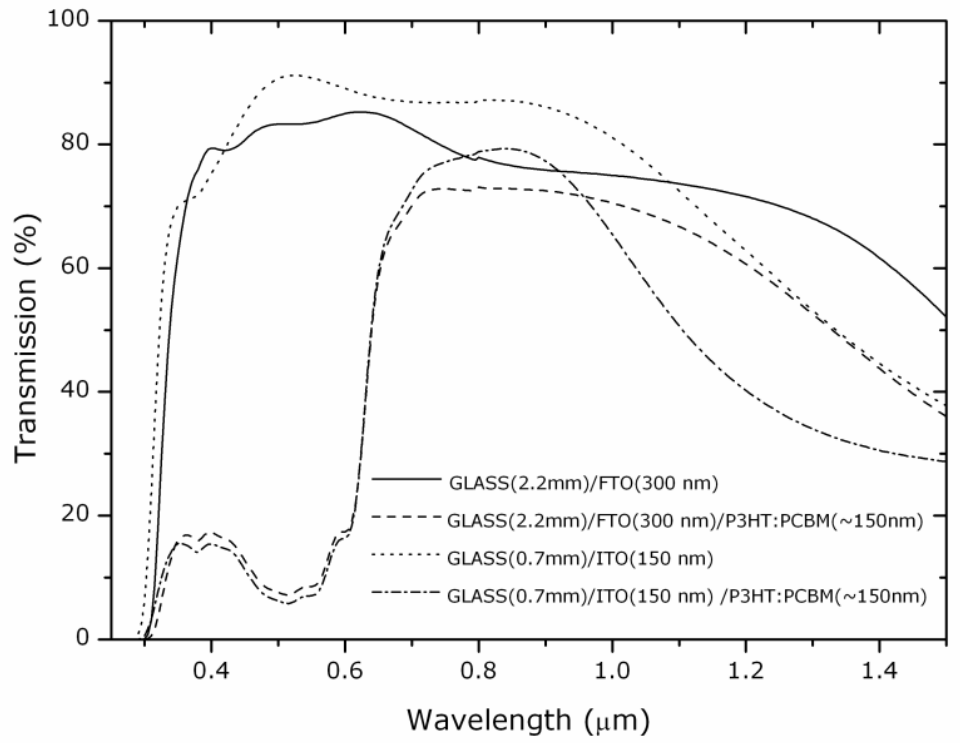

Figure 3. Optical transmission spectra for conductive oxide coated glass substrates and active layer coated substrates before $\mathrm{BCP} / \mathrm{Al}$ deposition 


\section{CONCLUSIONS}

A performance comparison of ITO and FTO based P3HT and [6,6]-phenyl-C71-butyric acid methyl ester $\left(\mathrm{PC}_{70} \mathrm{BM}\right)$ bulk heterojunction PVs with and without PEDOT:PSS hole extraction layers was presented. It is concluded that FTO performs as well as ITO, with slightly lower $\mathrm{J}_{\mathrm{sc}}$ owing to higher optical absorption of FTO leading to a reduction in available photons for photogeneration. Devices without the hole extraction layer yield better PVs under the device architecture used, with similar FFs for FTO as well as ITO, suggesting the work function differences of the two conducting oxides affect insignificantly for the device performance. The performance of cheaper and more readily available FTO compares well with the more expensive ITO in terms of measured device efficiency, which bodes well for future mass production.

\section{ACKNOWLEDGMENTS}

Part of this work is based on a project funded by E.ON AG, as part of the E.ON International Research Initiative. Responsibility for the content of this publication lies with the authors.

\section{REFERENCES}

[1] R. F. Service, Science 319, 718-720 (2008).

[2] J. J. M. Halls, C. A. Walsh, N. C. Greenham, E. A. Marseglia, R. H. Friend, S. C. Moratti, and A. B. Holmes, Nature 376, 498-500 (1995).

[3] G. Yu, J. Gao, J. C. Hummelen, F. Wudl, and A. J. Heeger, Science, 270, 1789-91 (1995).

[4] G.Li, V. Shrotriya, H. Jinsong, Y. Yan, T. Moriarty, K. Emery, and Y. Yang, Nature Materials, 4, 864-8, (2005).

[5] K. Jin Young, L. Kwanghee, N. E. Coates, D. Moses, N. Thuc-Quyen, M. Dante, and A. J. Heeger, Science, 317, 222-5 (2007).

[6] G. Dennler, M. C. Scharber, and C. J. Brabec, Advanced Materials, 21, 1323-1338 (2009).

[7] H.-Y. Chen, J. Hou, S. Zhang, Y. Liang, G. Yang, Y. Yang, L. Yu, Y. Wu, and G. Li, Nat Photon. 3, 649-653 (2009).

[8] R. Valaski, R. Lessmann, L. S. Roman, I. A. Hümmelgen, R. M. Q. Mello, and L. Micaroni, Electrochemistry Communications, 6, 357-360 (2004).

[9] R. Valaski, F. Muchenski, R. Mello, L. Micaroni, L. Roman, and I. Hümmelgen, Journal of Solid State Electrochemistry, 10, 24-27 (2006).

[10] M. W. Rowell, M. A. Topinka, M. D. McGehee, H.-J. Prall, G. Dennler, N. S. Sariciftci, L. Hu, and G. Gruner, Applied Physics Letters, 88, 233506 (2006).

[11] F. Yang and S. R. Forrest, Advanced Materials, 18, 2018-2022 (2006).

[12] H. Kim, G. P. Kushto, R. C. Y. Auyeung, and A. Pique, Applied Physics A: Materials Science and Processing, 93, 521-526 (2008).

[13] A. Andersson, N. Johansson, P. Broems, N. Yu, D. Lupo, and W. R. Salaneck, Advanced Materials, 10, 859-863 (1998). 